\title{
Cronkhite-Canada syndrome: A case report
}

\author{
WEI YUAN ${ }^{1,2}$, LI TIAN $^{1}$, FEI-YAN AI ${ }^{1}$, SHAO-JUN LIU $^{1}$, SHOU-RONG SHEN $^{1}$, \\ XIAO-YAN WANG ${ }^{1}$ and FEN LIU ${ }^{1}$
}

\author{
${ }^{1}$ Department of Gastroenterology, Hunan Key Laboratory of Non-Resolving Inflammation and Cancer, The Third Xiangya \\ Hospital of Central South University, Changsha, Hunan 410013; ${ }^{2}$ Department of Hepatology, The First Affiliated Hosipital \\ of Hu-Nan University of Chinese Medicine, Changsha, Hunan 410007, P.R. China
}

Received July 23, 2016; Accepted December 12, 2017

DOI: $10.3892 / \mathrm{ol} .2018 .8409$

\begin{abstract}
Cronkhite-Canada syndrome (CCS) is a rare non-inherited condition characterized by gastrointestinal (GI) hamartomatous polyposis, alopecia, onychodystrophy, hyperpigmentation, weight loss and diarrhea. The etiology is most likely autoimmune and diagnosis is based on patient history, physical examination, endoscopic findings of GI polyposis and histology. The disease is very rare; thus far more than 500 cases of CCS have been reported globally. A 58-years-old male with CCS was reported in the present case study. The patient experienced a history of diarrhea and hematochezia for 4 months, with abdominal pain for 1 month and additional nail and toenail loss for half a month. The clinical, endoscopic and histological data confirmed the diagnosis.
\end{abstract}

\section{Introduction}

Cronkhite-Canada syndrome (CCS), also known as polyposis pigmentation-alopecia-onycholrophia syndrome, is a syndrome distinguished by gastrointestinal (GI) polyposis and ectodermal changes (1). It has been demonstrated that the incidence of CCS is 1 in a million (2). CCS affects more men compared with women, with a ratio of $3: 2$, and commonly occurs in the fifth decade of life, with a mean age of onset between 50-60 years (3). Cronkhite and Canada first described CCS in 1955, and CCS is a rare disease of unknown etiology (4). Following its identification, $>500$ cases have been described in the literature (5). Although the incidence of CCS is low, it is associated with a high mortality; 5-year mortality may be as high as $55 \%$ (6). At present, the treatments for CSS include corticosteroids, nonsteroidal anti-inflammatory drugs, proton pump inhibitors, H2-receptor antagonists, hyperalimentation,

Correspondence to: Dr Fen Liu, Department of Gastroenterology, Hunan Key Laboratory of Non-Resolving Inflammation and Cancer, The Third Xiangya Hospital of Central South University, 138 Tongzipo Road, Changsha, Hunan 410013, P.R. China E-mail: liufencsu@163.com

Key words: Cronkhite-Canada syndrome, hyperpigmentation, polyposis, onychodystrophy cromolyn sodium, antibiotics, anabolic steroids, surgery, 5-aminosalicylate acid, antitumor necrosis factor $\alpha$ agents and the eradication of Helicobacter pylori, or a combination of these therapies (7).

In the present case study, a 58-years-old male with CCS diagnosed at the Department of Gastroenterology, The Third Xiangya Hospital of Central South University (Hunan, China) is reported. The patient experienced a history of diarrhea and hematochezia for 4 months, with abdominal pain for 1 month and additional nail and toenail loss for half a month. The clinical, endoscopic and histological data confirmed the diagnosis. The patient was treated with proton pump inhibitors, gastric mucosal protective agents, endoscopic electrocision of colon polyps, glutamine capsule, nutrition support and Bifid triple viable capsules. The patient eventually recovered.

\section{Case report}

A 58-year-old male visited The Third Xiangya Hospital of Central South University (Hunan, Changsha, China) on June 6, 2014, with the primary complaint of diarrhea and hematochezia for 4 months, abdominal pain for 1 month and nail and toenail loss for half a month. Informed written consent was obtained from the patient for publication of the present study. The patient additionally felt tiredness and had experienced a weight loss of $5 \mathrm{~kg}$ in half a month. There were no abnormalities, including GI polyposis or colorectal cancer, in the family history of the individual. However, the patient had a history of alcoholic cirrhosis for $>10$ years, and 13 years prior to visiting The Third Xiangya Hospital of Central South University he had suffered from gastrorrhagia. The patient had been drinking $400 \mathrm{ml}$ rice wine and smoking 20 cigarettes/day for 40 years.

Physical examination revealed that the patient was suffering from malnutrition, he was emaciated and had an anemic appearance, with a dermatological triad of hyperpigmentation in his oral mucosa (Fig. 1) and a brown pigmentation in his palms and feet (Fig. 2). Atrophy of fingernail and toenails were later observed, in addition to eventual toenail and nail loss.

Laboratory tests revealed that the patient's white blood cell count was $7.5 \times 10^{9} / 1$ (normal range, $4-10 \times 10^{9} / 1$ ), platelet count was $216 \times 10^{9} / 1$ (normal range, $100-300 \times 10^{9} / 1$ ), hemoglobin was $61 \mathrm{~g} / 1$, fecal occult blood test (+), C-reactive protein and erythrocyte sedimentation rate were normal, serum albumin was 


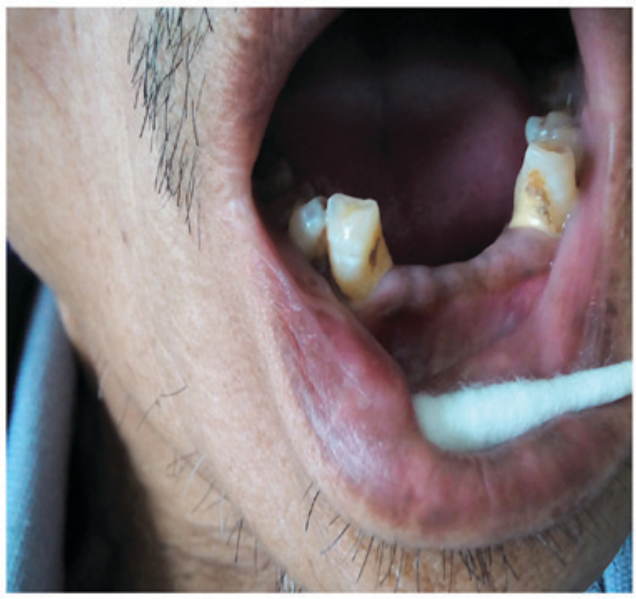

Figure 1. Black-brown pigmentation was identified in the oral mucosa of a patient with Cronkhite-Canada syndrome.

$28.5 \mathrm{~g} / 1$ (normal range, $40-60 \mathrm{~g} / \mathrm{l}$ ) and serum total protein was $46.1 \mathrm{~g} / 1$ (normal range, $60-80 \mathrm{~g} / \mathrm{l})$.

Esophagogastroduodenoscopy, performed for the further evaluation of the GI tract, revealed multiple nodules and granular polyps in the stomach and duodenum (Fig. 3).

In the present study, biopsy specimens were fixed in $4 \%$ paraformaldehyde at room temperature, dehydrated (75\% ethanol for $45 \mathrm{~min}, 85 \%$ ethanol for $45 \mathrm{~min}$, 95\% ethanol for $45 \mathrm{~min}, 100 \%$ ethanol for $45 \mathrm{~min}$, immersed in $100 \%$ isobutanol overnight and lastly transferred to $100 \%$ butanol for $3 \mathrm{~h}$ ) and embedded in paraffin. Paraffin-embedded sections measuring $4 \mu \mathrm{m}$-thick were then stained with $0.5 \%$ hematoxylin for $2 \mathrm{~min}$ and $1 \%$ eosin for $1 \mathrm{~min}$ at room temperature (H\&E). Finally, the sections were observed under a light microscope (magnification, x100; Olympus BX51; Olympus Corporation, Tokyo, Japan,).

Biopsy specimens from the gastric antrum mucosa displayed mucosal chronic inflammation, edematous stroma with inflammatory cell infiltration, small blood vessel proliferation and regional glandular epithelial hyperplasia (Fig. 4).

As these findings could not confirm the diagnosis, a further colonoscopy was performed for differential diagnosis, which revealed numerous, dense polyps throughout the terminal ileum, colon and rectum (Figs. 5 and 6). Biopsy specimens from the colon displayed colorectal villus-tubiform adenoma, glandular epithelial hyperplasia and mild-to-moderate atypical hyperplasia (Fig. 7). GI radiography revealed that the GI multiple filling defect may be a result of the multiple polyps (Fig. 8).

The patient presented with diffuse GI polyposis associated with ectodermal changes including hyperpigmentation and onychatrophy, and these findings resulted in the diagnosis of CCS. We intended to treat the patient with corticosteroids, but he refused due to the potential side-effects. Therefore, the patient was treated with proton pump inhibitors to inhibit gastric acid secretion (40\% pantoprazole sodium, $100 \mathrm{ml}$, was administered intravenously, once a day), gastric mucosal protective agents to protect gastric mucosa (Hydrotalcite Chewable Tablets, $1 \mathrm{~g}$, orally, three times a day), endoscopic electrocision of colon polyps, glutamine to protect the intestinal intima (3\% alanine glutamine, $50 \mathrm{ml}$, ivgtt, once a day) and nutritional
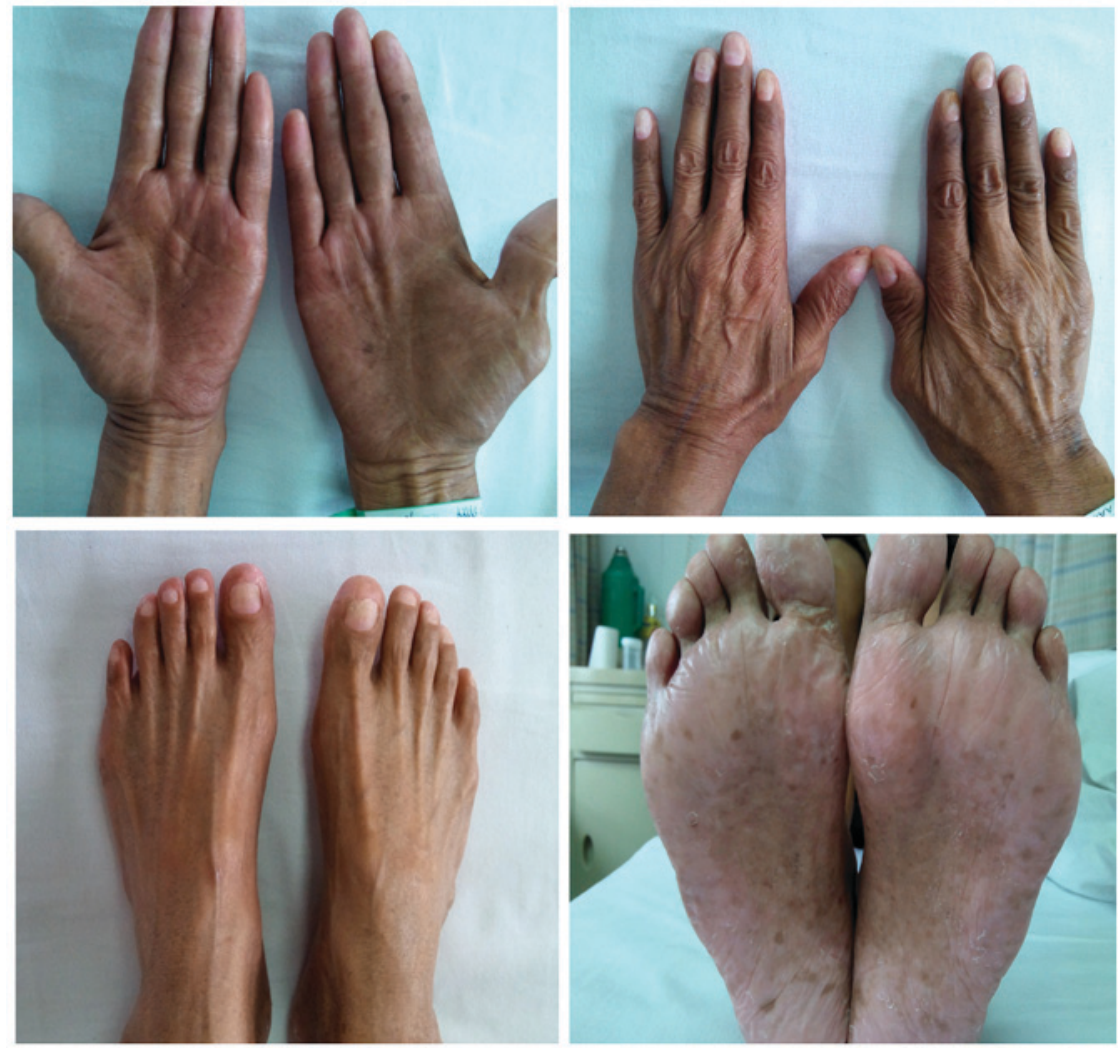

Figure 2. Black-brown pigmentation was observed in the palms and feet of a patient with Cronkhite-Canada syndrome, with toenail and nail changes additionally observed. Changes in the shape and color of toenail and nail. 


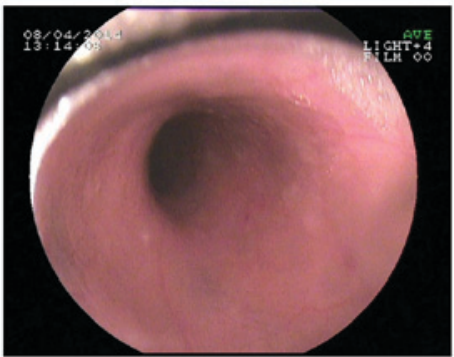

Esophagus

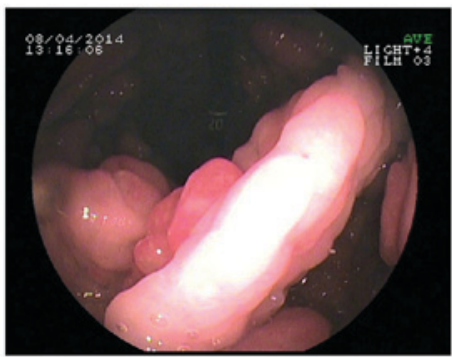

Gastric angle

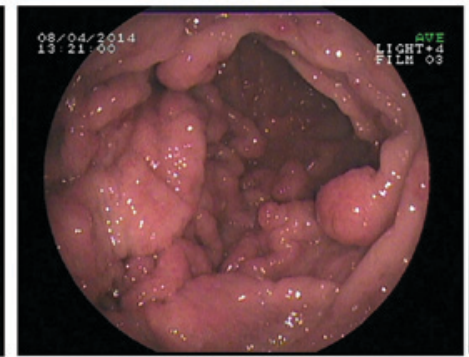

Gastric body

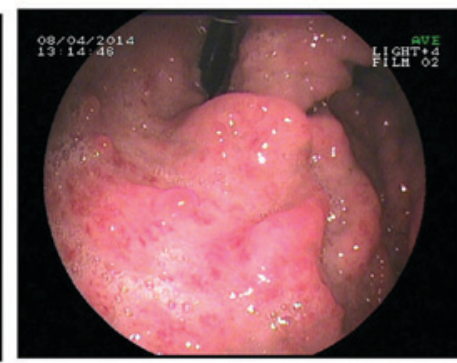

Cardia and fundus ventriculi

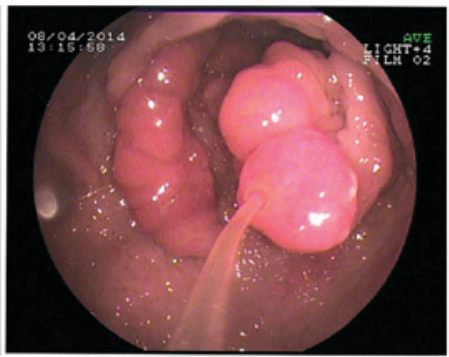

Antrum

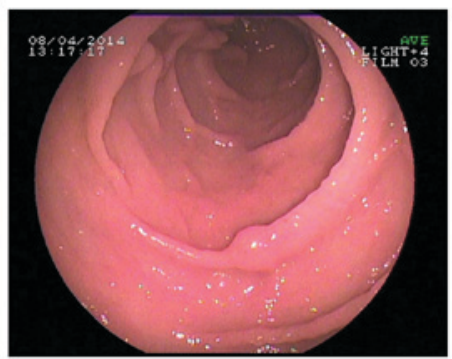

Descending duodenuim

Figure 3. Multiple nodules and granular polyps identified in the stomach and duodenum.

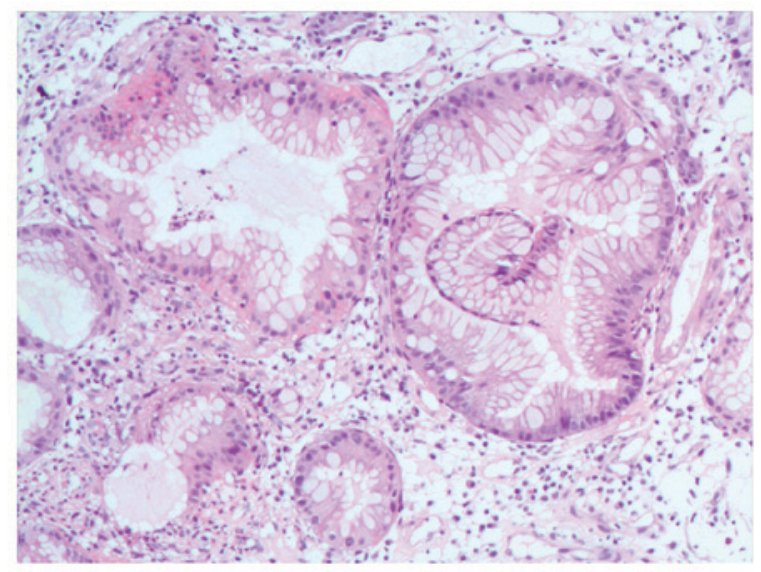

Figure 4. Biopsy specimen from gastric antrum mucosa displayed mucosal chronic inflammation, edematous stroma with inflammatory cell infiltration, small blood vessel proliferation and regional glandular epithelial hyperplasia (hematoxylin \& eosin stain; magnification x100).

support (7\% amino acid compound infusion18AA-II, $250 \mathrm{ml}$ ivgtt, once a day). We also used bifid triple viable capsules to modulate intestinal flora (Bifid triple viable capsules, $420 \mathrm{mg}$, orally, three times a day). The patient eventually recovered and was discharged from the hospital within 1 month.

Following 1 month of treatment, gastroscopy revealed gastric duodenal mucosal swelling and mucous with nodular and polypoid hyperplasia (Fig. 9). Biopsy specimens from the gastric antrum mucosal displayed mucosal chronic inflammation, regional glandular epithelial hyperplasia and a growth tendency of inflammatory hyperplastic polyps with inflammatory cell infiltration (Fig. 10). Colonoscopy revealed terminal ileum, colon and rectal hyperplastic polyps, with colon polyps emerging subsequent to endoscopic mucosal resection and titanium clip clipping operation (Figs. 11 and 12). Biopsy specimens from the colon displayed a tubular adenoma $40 \mathrm{~cm}$ from the anus and ascending colon. Additionally, part of the glandular epithelium had light-mild atypical hyperplasia, a stroma of acidophilic ball infiltration (in the terminal ileum and appendix) and mucosal chronic inflammation (in the appendix) within the interstitial eosinophilic inflammation (Fig. 13). In order to exclude lymphoma, ultrasonic gastroscopy was advised, and the patient was further advised to take corticosteroids, but he refused and asked for discharging from the hospital following 1 month of treatment.

\section{Discussion}

Cronkhite and Canada first described CCS in 1955 (4). CCS is a rare, acquired, nonhereditary syndrome with diffuse GI polyposis associated with ectodermal changes, including hyperpigmentation, alopecia and onychatrophy $(8,9)$. Additionally, it has been reported that the CCS has been associated with poor prognosis and life-threatening malignant complications (7). The etiology of CCS remains unknown, and genetic abnormalities (10), mental stress (11), immune dysregulation $(12,13)$, low turnover cell differentiation (14) and fatigue are regarded as triggering factors for CCS (2).

CCS may occur in all ethnic groups, and the estimated incidence of CCS is extremely rare, approximately one case in a million individuals (2). At present, $>500$ cases of CCS have been reported globally, and patients from Europe and Asia are most frequently affected (2). Of all reported cases of CCS, $75 \%$ have been from Japan (15).

Furthermore, it has been reported that CCS is sporadic and there is no strong evidence to suggest a hereditary predisposition (2). CCS affects more men compared with women, with a ratio of $3: 2$, and commonly occurs in the fifth decade of life. A total of $80 \%$ of patients are $>50$ years of age at the time of presentation (6). According to a previous study, it has been revealed that the mean age of onset of CCS is 63.5 (range, 31-86) years (7).

CCS is also known as polyposis pigmentation-alopeciaonycholrophia syndrome, and GI polyposis and ectodermal 

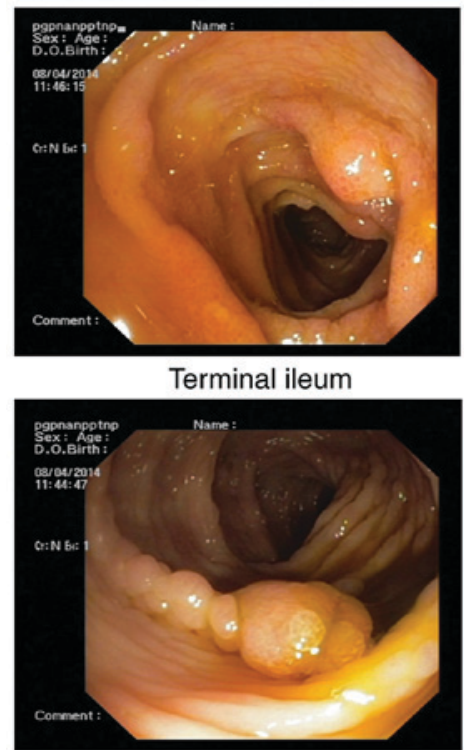

Colon

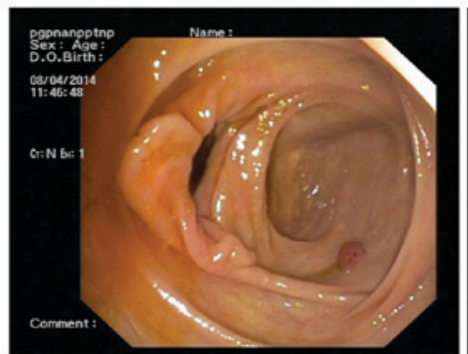

Ileocecal valve

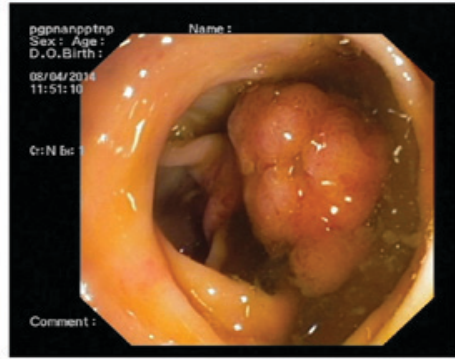

Rectum

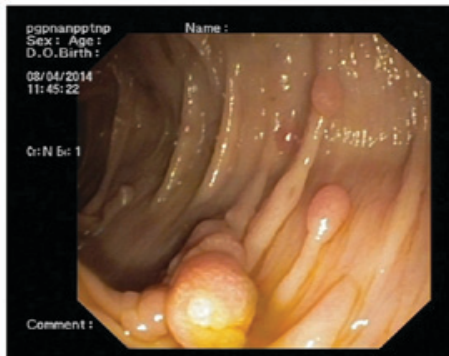

Ascending colon

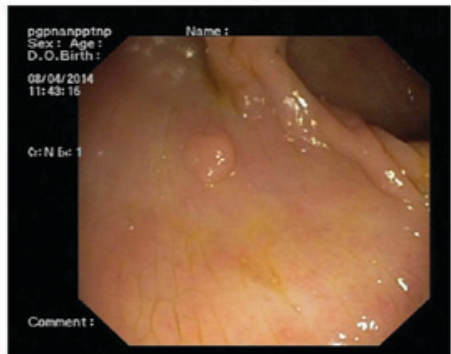

Rectum

Figure 5. Numerous polyps were observed throughout the terminal ileum, colon and rectum prior to treatment.
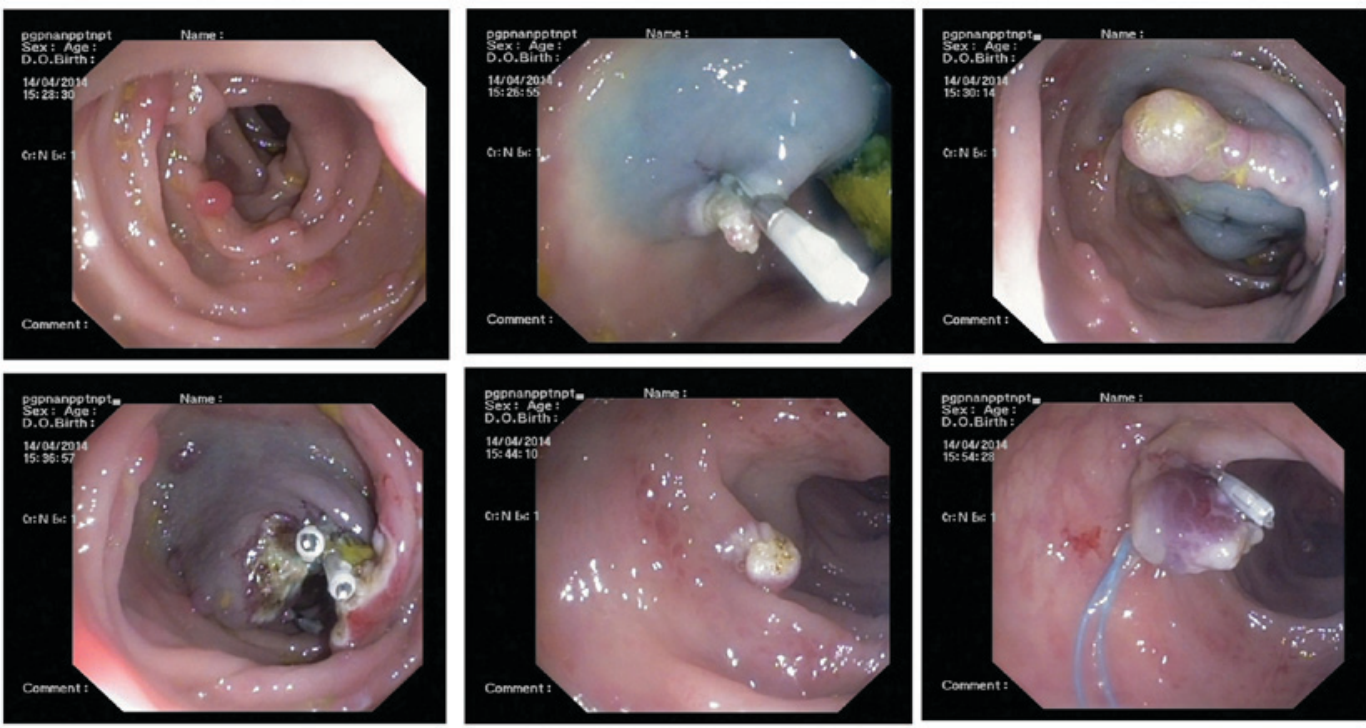

Figure 6. Colonoscopy was performed subsequent to the endoscopic electric resection of colon polyps.

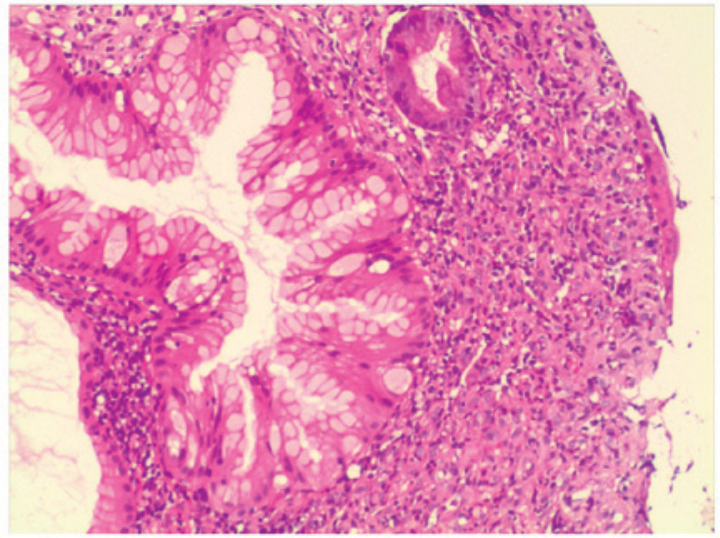

Figure 7. Biopsy specimen from colon displayed colorectal villus-tubiform adenoma, glandular epithelial hyperplasia and mild-to-moderate atypical hyperplasia (hematoxylin \& eosin stain; magnification, x100). changes are its two main features (16). For patients with CCS, diarrhea is the most common initial symptom, which may develop to substantially watery diarrhea, followed with symptoms of malabsorption, including weakness, anemia, weight loss, edema and dysgeusia (17). Subsequent endoscopic and radiological evaluation may reveal sessile polyps throughout the GI tract (18).

Histopathological reviews of biopsies obtained from these polyps revealed that these polyps are similar to that of juvenile, adenomatous polyps or inflammatory type polyps, however they were additionally marked by striking stromal and lamina propria edematous changes, eosinophilic inflammation, were cystically dilated and had distorted glands with inflammatory infiltration (7).

Ectodermal changes include alopecia, nail dystrophy and hyperpigmentation. These changes often occur later during 


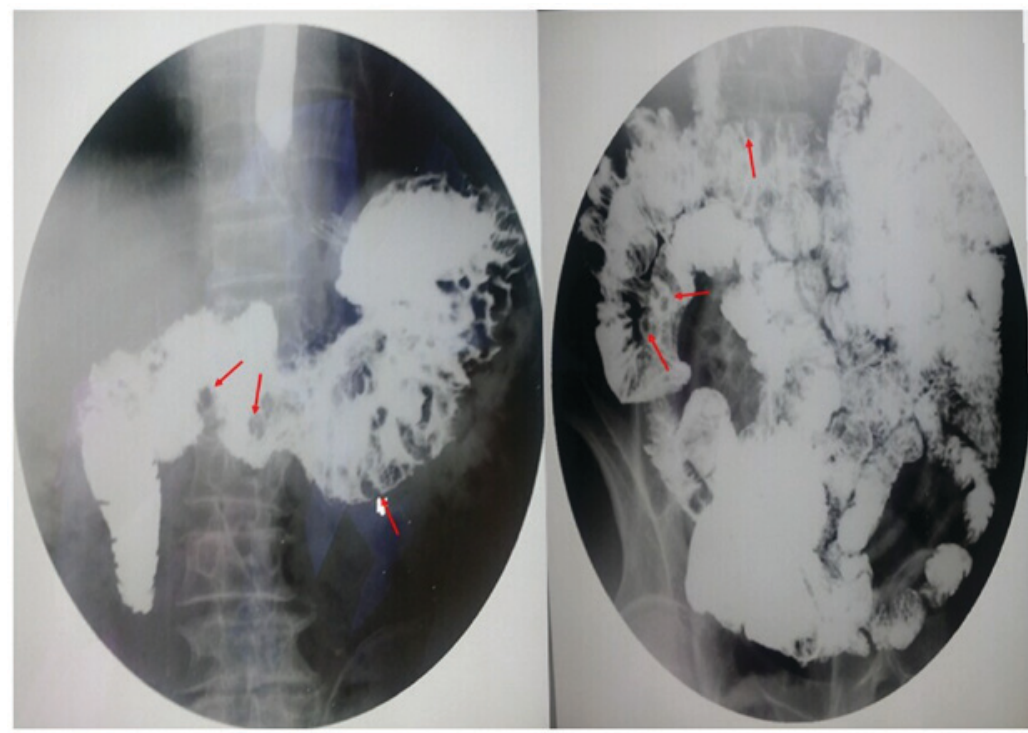

Figure 8. An upper gastrointestinal barium study with small bowel follow-through revealing multiple polyps in the stomach, duodenum and small bowel. Red arrows indicate polyps.

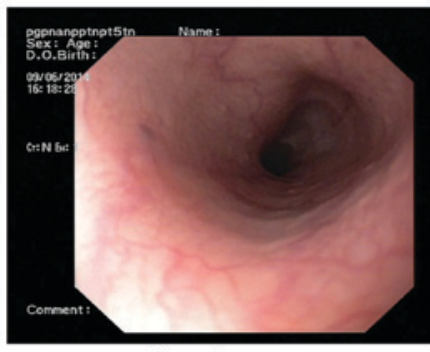

Esophagus

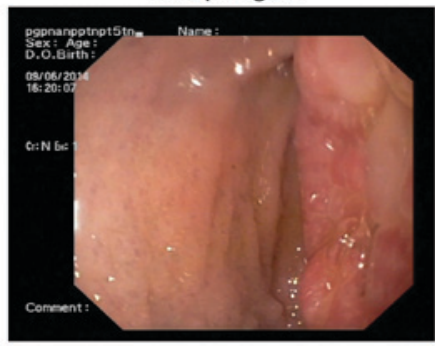

Duodenal bulb

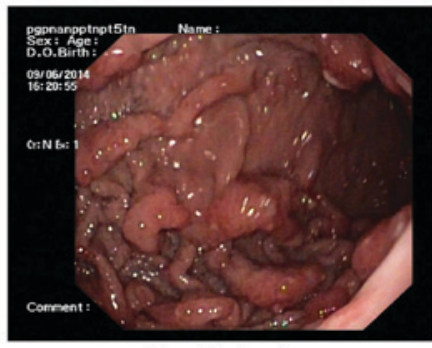

Gastric body

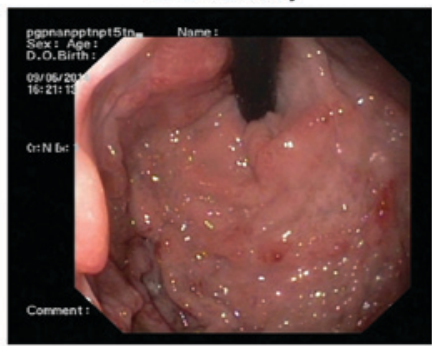

Cardia and fundus rentriculi

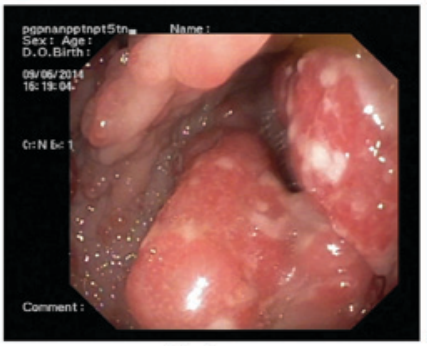

Antrum

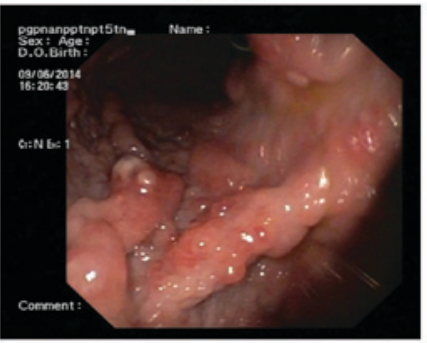

Gastric angle

Figure 9. Numerous nodular and polypoid hyperplasia were identified in the gastrointestinal tract and the duodenum.

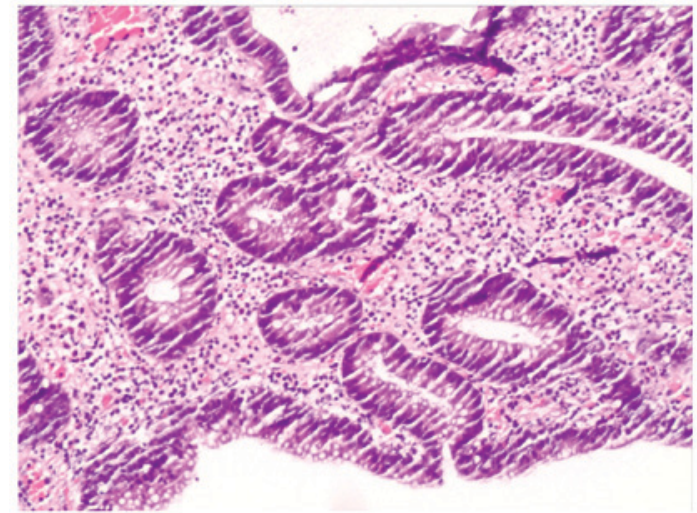

Figure 10. Biopsy specimen from gastric antrum mucosa displayed mucosal chronic inflammation, regional glandular epithelial hyperplasia, growth tendency of inflammatory hyperplastic polyp with inflammatory cell infiltration. (hematoxylin \& eosin stain; magnification, $\mathrm{x} 100$ ). the disease progression, usually several weeks or months subsequent to the GI symptoms (8). Consistent with this, in the present case study, the patient initially experienced diarrhea and hematochezia, followed by abdominal pain, nail and toenail loss, onychatrophy and hyperpigmentation.

Complications of CCS include GI bleeding with anemia, intussusception, hypoproteinemia, rectal prolapse, malabsorption, electrolyte turbulences, enteropathy and hypovitaminosis (19). In addition, CCS was reported to be associated with various rare complications including recurrent severe acute pancreatitis (20), GI tract cancer, portal thrombosis, a high titer of antinuclear antibodies and membranous glomerulonephritis (21). Among them, the risk of GI tract tumor types substantially increases. It has been reported that between 1980 and 2011, there were 383 patients diagnosed with CCS in Japan, and of these patients, $10.4 \%$ 

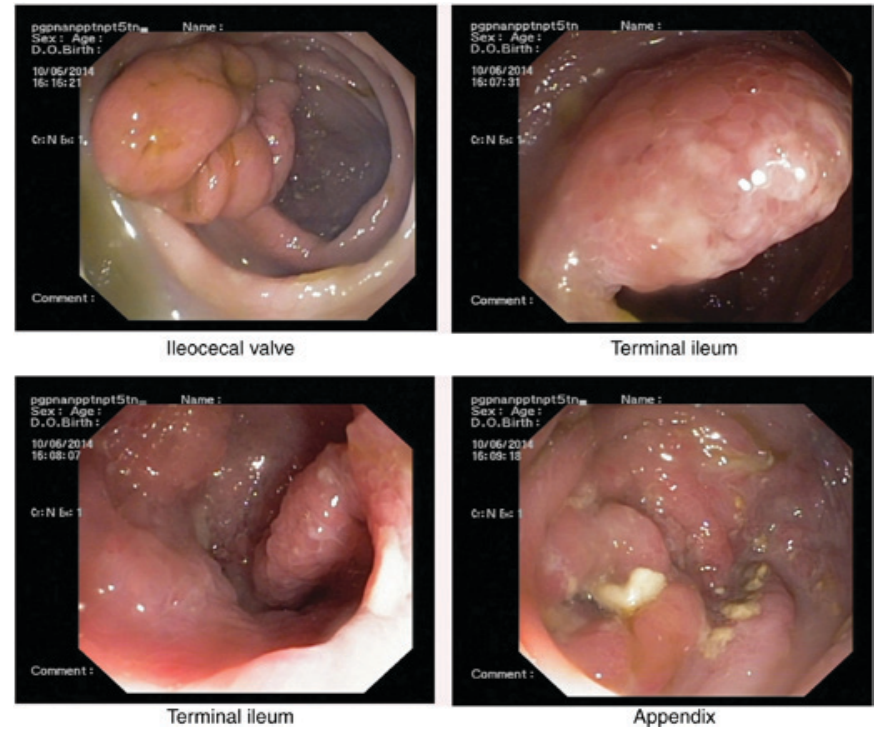

Figure 11. Numerous polyps were observed throughout the terminal ileum, colon and rectum.

(40 patients) of them were also diagnosed with gastric cancer and 69 lesions (51 patients) were also diagnosed with colon cancer (15). Due to this, endoscopic surveillance is strongly recommended.

Differential diagnosis of CCS includes Menetrier disease, familial adenomatous polyposis, juvenile polyposis, Cowden syndrome, Peutz-Jeghers syndrome, inflammatory bowel disease, Whipple disease and small intestinal lymphoma (22-24). In the present case, the patient was initially diagnosed with familial polyposis, but eventually was diagnosed with CCS due to the dermatological triad of hyperpigmentation in oral mucosa (Fig. 1), brown pigmentation in palms and feet (Fig. 2) and toenail and nail loss.

Due to the rarity of CCS, evidence-based therapies have yet to be developed, however, to the best of our knowledge, there are no systematic investigations of medical or surgical

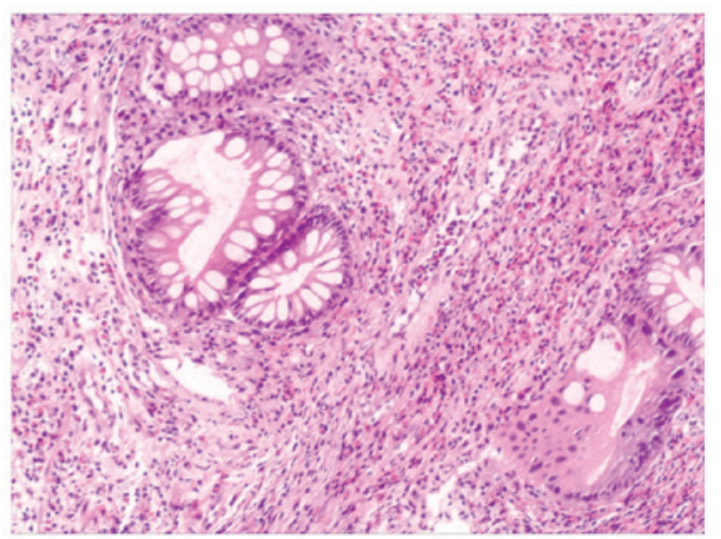

Figure 13. Biopsy specimen revealed a colon displaying a tubular adenoma (40 $\mathrm{cm}$ from the anus and ascending colon), part of the glandular epithelium with light-mild atypical hyperplasia, stroma of eosinophilic inflammation and mucosal chronic inflammation (in the terminal ileum and appendix; hematoxylin \& eosin stain; magnification, x100).

interventions. The treatments and strategy of CSS currently include corticosteroids, nonsteroidal anti-inflammatory drugs, proton pump inhibitors, H2-receptor antagonists, hyperalimentation, cromolyn sodium, antibiotics, anabolic steroids, surgery, 5-aminosalicylate acid, antitumor necrosis factor $\alpha$ agents and the eradication of Helicobacter pylori and combinations of these therapies (7). Steroids are considered to be the mainstay of medical treatment, however until now, there have been no guidelines for the recommended dose and duration of their use.

The prognosis of CCS is poor, with a 5-year mortality rate of $55 \%$ and the majority of mortality being associated with malnutrition, hypoalbuminemia, repetitive infection, sepsis, heart failure and GI bleeding (8). The natural history of CCS appears to be substantially improved owing to the sufficient dose and duration of corticosteroid therapy accompanied by nutritional support and periodic endoscopic surveillance (7).
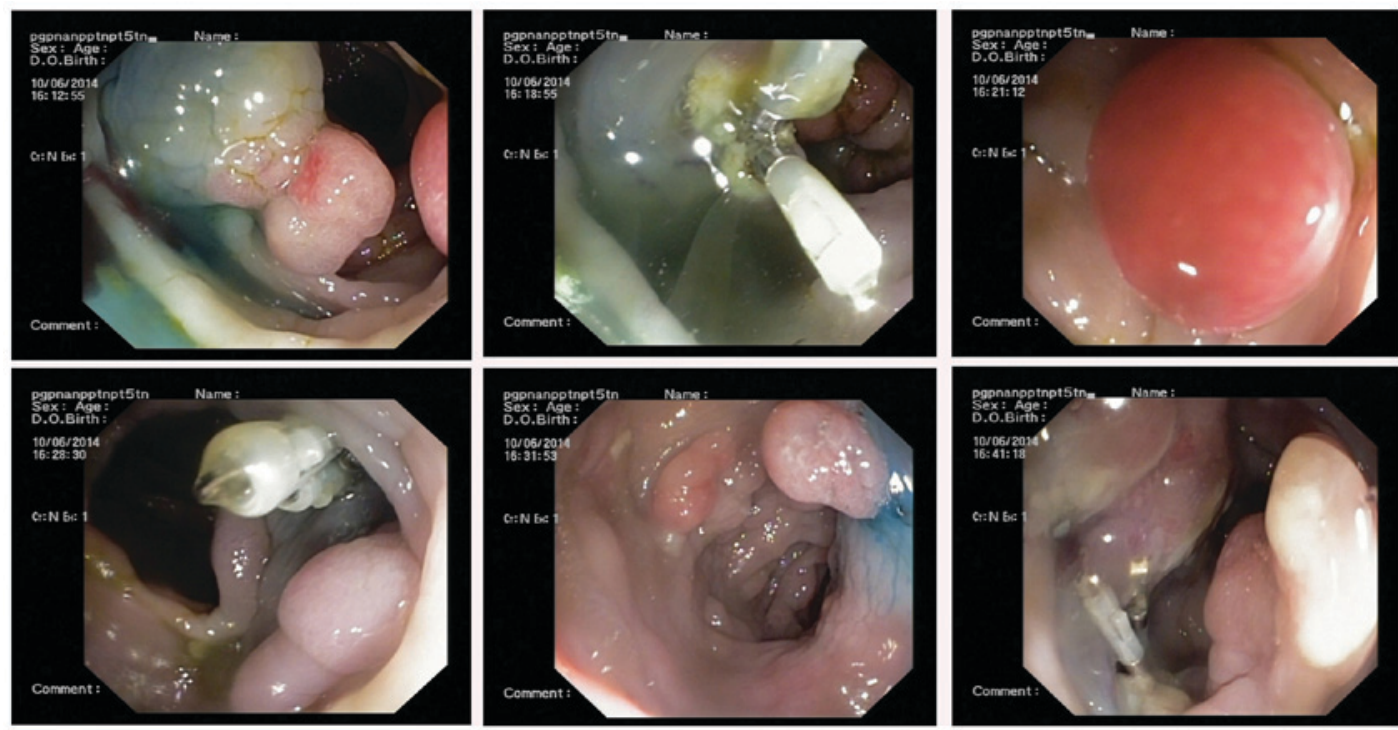

Figure 12. A colonoscopy was performed subsequent to an endoscopic mucosal resection and titanium clipping operation. 
Altogether, when a patient presents with the symptoms of CCS, early diagnosis and treatment of CCS is necessary, in addition to receiving endoscopic follow-up or polypectomy when necessary. In the present case, the results from a telephone follow-up implied that the patient is in a good condition; he feels well and does not experience any symptoms, therefore has refused to return to the hospital for a follow-up.

CCS is a rare but serious disease with an increased mortality rate if clinical intervention is received late (25). Delays in diagnosis are common, primarily due to the non-familiarity of physicians with this rare entity, resulting in a poor outcome (26). This patient did not present with the cardinal manifestations of CCS which resulted in a delayed diagnosis. Therefore, in order to avoid the misdiagnosis of CCS without typical features in future, physicians are recommended to analyze the histopathology of the polyps and to search for the presence of characteristic dermatological changes: The changes in the shape and colour of toenail and nail abnormalities.

\section{Acknowledgements}

The present case study was supported by the National Natural Science Foundation of China (grant nos. 81272736, 81670504 and 81472287), the National Key Clinical Specialty of National Health and Family Planning Commission and The Third Xiangya Hospital 'Xiangya Doctors Heritage Plan'.

\section{References}

1. Sweetser S, Alexander GL and Boardman LA: A case of Cronkhite-Canada syndrome presenting with adenomatous and inflammatory colon polyps. Nat Rev Gastroenterol Hepatol 7: 460-464, 2010

2. Goto A: Cronkhite-Canada syndrome: Epidemiological study of 110 cases reported in Japan. Nihon Geka Hokan 64: 3-14, 1995.

3. Ward EM and Wolfsen HC: Review article: The non-inherited gastrointestinal polyposis syndromes. Aliment Pharmacol Ther 16: 333-342, 2002.

4. Gardner EJ, Burt RW and Freston JW: Gastrointestinal polyposis: Syndromes and genetic mechanisms. West J Med 132: 488-499, 1980.

5. Rubio CA and Björk J: Cronkhite-Canada syndrome-A case report. Anticancer Res 36: 4215-4217, 2016.

6. Daniel ES, Ludwig SL, Lewin KJ, Ruprecht RM, Rajacich GM and Schwabe AD: The Cronkhite-Canada syndrome. An analysis of clinical and pathologic features and therapy in 55 patients. Medicine 61: 293-309, 1982.

7. Watanabe C, Komoto S, Tomita K, Hokari R, Tanaka M, Hirata I, Hibi T, Kaunitz JD and Miura S: Endoscopic and clinical evaluation of treatment and prognosis of Cronkhite-Canada syndrome: A Japanese nationwide survey. J Gastroenterol 51: 327-336, 2016.

8. Yun SH, Cho JW, Kim JW, Kim JK, Park MS, Lee NE, Lee JU and Lee YJ: Cronkhite-Canada syndrome associated with serrated adenoma and malignant polyp: A case report and a literature review of 13 cronkhite-Canada syndrome cases in Korea. Clin Endosc 463: 301-305, 2013.
9. Wen XH, Wang L, Wang YX and Qian JM: Cronkhite-Canada syndrome: Report of six cases and review of literature. World J Gastroenterol 20: 7518-7522, 2014.

10. Patil V, Patil LS, Jakareddy R, Verma A and Gupta AB Cronkhite-Canada syndrome: A report of two familial cases. Indian J Gastroenterol 32: 119-122, 2013.

11. Murata I, Yoshikawa I, Endo M, Tai M, Toyoda C, Abe S, Hirano Y and Otsuki M: Cronkhite-Canada syndrome: Report of two cases. J Gastroenterol 35: 706-711, 2000.

12. Sweetser S, Ahlquist DA, Osborn NK, Sanderson SO, Smyrk TC, Chari ST and Boardman LA: Clinicopathologic features and treatment outcomes in Cronkhite-Canada syndrome: Support for autoimmunity. Dig Dis Sci 57: 496-502, 2012.

13. Riegert-Johnson DL, Osborn N, Smyrk T and Boardman LA: Cronkhite-Canada syndrome hamartomatous polyps are infiltrated with IgG4 plasma cells. Digestion 75: 96-97, 2007.

14. Freeman K, Anthony PP, Miller DS and Warin AP: Cronkhite Canada syndrome: A new hypothesis. Gut 26: 531-536, 1985.

15. Matsui S, Kibi M, Anami E, Anami T, Inagaki Y, Kanouda A, Yoshinaga H, Watanabe A, Sugahara A, Mukai H, et al: A case of Cronkhite-Canada syndrome with multiple colon adenomas and early colon cancers. Nihon Shokakibyo Gakkai Zasshi 108: 778-786, 2011 (In Japanese).

16. Wang J,Zhao L, Ma N, Che J, Li H and Cao B: Cronkhite-Canada syndrome associated with colon cancer metastatic to liver: A case report. Medicine (Baltimore) 968: e7466, 2017.

17. Chakrabarti S: Cronkhite-Canada syndrome (CCS)-A rare case report. J Clin Diagn Res 9: OD08-OD09, 2015.

18. Goto A, Mimoto H, Shibuya C and Matsunami E: Cronkhite-Canada syndrome: An analysis of clinical features and follow-up studies of 80 cases reported in Japan. Nihon Geka Hokan 57: 506-526, 1988.

19. Seshadri D, Karagiorgos N and Hyser MJ: A case of cronkhite-Canada syndrome and a review of gastrointestinal polyposis syndromes. Gastroenterol Hepatol (NY) 8: 197-201, 2012.

20. Yasuda T, Ueda T, Matsumoto I, Shirasaka D, Nakajima T, Sawa H, Shinzeki M, Kim Y, Fujino Y and Kuroda Y: Cronkhite-Canada syndrome presenting as recurrent severe acute pancreatitis. Gastrointest Endosc 67, 570-572, 2008

21. Takeuchi Y, Yoshikawa M, Tsukamoto N, Shiroi A, Hoshida Y, Enomoto Y, Kimura T, Yamamoto K, Shiiki H, Kikuchi E and Fukui H: Cronkhite-Canada syndrome with colon cancer, portal thrombosis, high titer of antinuclear antibodies, and membranous glomerulonephritis. J Gastroenterol 38: 791-795, 2003.

22. Sweetser S and Boardman LA: Cronkhite-Canada syndrome: An acquired condition of gastrointestinal polyposis and dermatologic abnormalities. Gastroenterol Hepatol (NY) 8: 201-203, 2012.

23. Samet JD, Horton KM, Fishman EK and Iacobuzio-Donahue CA: Cronkhite-Canada syndrome: Gastric involvement diagnosed by MDCT. Case Rep Med 2009: 148795, 2009.

24. Kopáčová M, Urban O, Cyrany J, Laco J, Bureš J, Rejchrt S, Bártová J and Tachecí I: Cronkhite-Canada syndrome: Review of the literature. Gastroenterol Res Pract 2013: 856873, 2013.

25. Iqbal U, Chaudhary A, Karim MA, Anwar H and Merrell N: Cronkhite-Canada syndrome: A rare cause of chronic diarrhea. Gastroenterology Res 10: 196-198, 2017.

26. Fan RY, Wang XW, Xue LJ, An R and Sheng JQ: Cronkhite-Canada syndrome polyps infiltrated with IgG4-positive plasma cells. World J Clin Cases 4: 248-252, 2016.

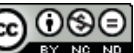

This work is licensed under a Creative Commons Attribution-NonCommercial-NoDerivatives 4.0 International (CC BY-NC-ND 4.0) License. 